OPEN ACCESS

Edited by:

Bin Ren,

Medical College of Wisconsin, USA

Reviewed by: Francisco Iñesta-Vaquera

University of Dundee, UK

Tomas Obsil,

Charles University, Czech Republic

'Correspondence: Fumio Sakane sakane@faculty.chiba-u.jp

Specialty section

This article was submitted to Signaling,

a section of the journa Frontiers in Cell and Developmental Biology

Received: 01 July 2016 Accepted: 29 July 2016 Published: 17 August 2016

Citation:

Sakane F, Mizuno S and Komenoi S (2016) Diacylglycerol Kinases as Emerging Potential Drug Targets for a Variety of Diseases: An Update.

Front. Cell Dev. Biol. 4:82 doi: 10.3389/fcell.2016.00082

\section{Diacylglycerol Kinases as Emerging Potential Drug Targets for a Variety of Diseases: An Update}

\author{
Fumio Sakane *, Satoru Mizuno and Suguru Komenoi \\ Department of Chemistry, Graduate School of Science, Chiba University, Chiba, Japan
}

Ten mammalian diacylglycerol kinase (DGK) isozymes $(\alpha-\kappa)$ have been identified to date. Our previous review noted that several DGK isozymes can serve as potential drug targets for cancer, epilepsy, autoimmunity, cardiac hypertrophy, hypertension and type II diabetes (Sakane et al., 2008). Since then, recent genome-wide association studies have implied several new possible relationships between DGK isozymes and diseases. For example, DGK $\theta$ and DGKk have been suggested to be associated with susceptibility to Parkinson's disease and hypospadias, respectively. In addition, the DGKn gene has been repeatedly identified as a bipolar disorder (BPD) susceptibility gene. Intriguingly, we found that DGKn-knockout mice showed lithium (BPD remedy)-sensitive mania-like behaviors, suggesting that DGK $\eta$ is one of key enzymes of the etiology of BPD. Because DGKs are potential drug targets for a wide variety of diseases, the development of DGK isozyme-specific inhibitors/activators has been eagerly awaited. Recently, we have identified DGK $\alpha$-selective inhibitors. Because DGK $\alpha$ has both pro-tumoral and anti-immunogenic properties, the DGK $\alpha$-selective inhibitors would simultaneously have anti-tumoral and pro-immunogenic (anti-tumor immunogenic) effects. Although the ten DGK isozymes are highly similar to each other, our current results have encouraged us to identify and develop specific inhibitors/activators against every DGK isozyme that can be effective regulators and drugs against a wide variety of physiological events and diseases.

Keywords: diacylglycerol kinase, bipolar disorder, hypospadias, Parkinson's disease, inhibitor, cancer, anti-tumor immunity

\section{INTRODUCTION}

Mammalian diacylglycerol kinase (DGK) represents a large enzyme family (Goto et al., 2006; Sakane et al., 2007; Mérida et al., 2008; Topham and Epand, 2009). To date, ten mammalian DGK isozymes, $\alpha$ (Sakane et al., 1990; Schaap et al., 1990), $\beta$ (Goto and Kondo, 1993), $\gamma$ (Goto et al., 1994; Kai et al., 1994), $\delta$ (Sakane et al., 1996), $\varepsilon$ (Tang et al., 1996), $\zeta$ (Bunting et al., 1996; Goto and Kondo, 1996), $\eta$ (Klauck et al., 1996), $\theta$ (Houssa et al., 1997), ı (Ding et al., 1998), and $\kappa$ (Imai et al., 2005), have been identified. Moreover, several alternative splicing products-such as $\delta 1$ and $\delta 2$ (Sakane et al., 2002); $\eta 1-\eta 3$ (Murakami et al., 2003; Shionoya et al., 2015); $\zeta 1$ and $\zeta 2$ (Ding et al., 1997), and ı1-ı3 (Ito et al., 2004)-have also been found. These isozymes contain two or three characteristic protein kinase C (PKC)-like $\mathrm{C} 1$ domains (cysteine-rich, zinc finger structures) and the catalytic region in common and are subdivided into five groups, type I ( $\alpha, \beta$ and $\gamma)$, II $(\delta, \eta$ and $\kappa)$, III $(\varepsilon), \operatorname{IV}(\zeta$ and $\iota)$, and 
$\mathrm{V}(\theta)$, according to their structural features (Goto et al., 2006; Sakane et al., 2007; Mérida et al., 2008; Topham and Epand, 2009). Each group is characterized by the subtype-specific functional domains, such as EF-hand motifs (type I), pleckstrin homology and sterile $\alpha$ motif domains (type II), ankyrin repeats (type IV), and ras-associating and pleckstrin homology domains (type V).

Our previous review (Sakane et al., 2008) showed that many interesting studies on DGK have brought DGK to the center stage of diverse biological events such as growth factor/cytokine-dependent cell proliferation and motility, seizure activity, immune responses, cardiovascular responses, and glucose metabolism. Therefore, from a medical point of view, DGK isoforms are implicated in the pathogenesis of a wide variety of diseases, for example, cancer, epilepsy, autoimmunity, cardiac hypertrophy, hypertension, and type II diabetes. Thus, DGKs have emerged as potential and attractive drug targets for curing these diseases.

Recent advances in genotyping technology have allowed for rapid genome-wide screening of common variants in large populations, launching a new era in the investigation of the genetic basis of complex diseases. DGK is no exception. Since our review was published (Sakane et al., 2008), additional interesting reports using genome-wide association studies (GWASs) have successively implied several new possible relationships between DGK isozymes and diseases. For example, DGKn (Baum et al., 2008; Ollila et al., 2009; Squassina et al., 2009; Weber et al., 2011; Zeng et al., 2011), DGKK (van der Zanden et al., 2011; Carmichael et al., 2013), and DGK $\theta$ (Pankratz et al., 2009; Simón-Sánchez et al., 2011) have been suggested to be associated with susceptibility to bipolar disorder (BPD), hypospadias, and Parkinson's disease, respectively.

Among these isozymes, based on the results obtained for the GWASs of DGKH (DGKn gene), we recently investigated the relationship between DGK $\eta$ and BPD. For this purpose, we generated DGK $\eta$-knockout $(\mathrm{KO})$ mice and used these mice to perform behavioral and pharmacological tests. Intriguingly, we found that DGKn-knockout mice showed lithium (BPD remedy)-sensitive mania-like behaviors, suggesting that DGK $\eta$ is one of key enzymes of the pathogenesis of BPD (Isozaki et al., 2016).

As mentioned in our previous review (Sakane et al., 2008), the development of DGK isozyme-specific inhibitors/activators is important both for fundamental research and for developing therapeutic strategies to treat a wide variety of pathological disorders. However, there was no available DGK isozymespecific inhibitor/activator until recently. We have recently identified DGK $\alpha$-selective inhibitors using a newly established high-throughput screening method (Sato et al., 2013). Because $\mathrm{DGK} \alpha$ has both pro-tumoral and anti-immunogenic properties, the DGK $\alpha$-selective inhibitors would simultaneously have antitumoral and pro-immunogenic (anti-tumor immunogenic) effects.

This mini review will focus primarily on the two abovementioned topics, recent GWASs and the development of DGK isozyme-specific inhibitors.

\section{GWAS-NEW POSSIBLE RELATIONSHIPS BETWEEN DGK ISOZYMES AND DISEASES \\ DGK $\eta$}

BPD is a highly heritable neuropsychiatric illness characterized by recurrent episodes of depression and mania or hypomania and affects up to $4 \%$ of the adult population worldwide (Bauer and Pfennig, 2005; Merikangas et al., 2007). Approximately 20\% of the patients die of suicide (Kilbane et al., 2009). Recent GWASs of BPD have proposed novel genetic candidates, including $D G K H$, which encodes DGK $\eta$. Baum et al. for the first time, reported a strong association between BPD and three SNPs (rs9315885, rs1012053, and rs1170191) located in the first intron of $D G K H$ by a GWAS in two independent samples of European origin (Baum et al., 2008; Table 1). Next, SNP rs9315885 was demonstrated to be associated with BPD in a Finnish family cohort (Ollila et al., 2009). In addition, six SNPs in DGKH including rs1170191 were associated with BPD in a German sample as well (Weber et al., 2011). Moreover, an association of DGKH with BPD has also been found in Sardinian (Squassina et al., 2009) and Chinese (Zeng et al., 2011) samples at the haplotype level. In addition, another study showed that BPD samples displayed significantly increased DGKH gene expression levels (25\% higher than in controls; Moya et al., 2010). These data imply that mutations of the DGKH gene are involved in BPD. However, other studies have not confirmed this association (Sklar et al., 2008; Tesli et al., 2009; Yosifova et al., 2009). Moreover, GWAS itself does not directly indicate a relationship between SNPs and diseases. Therefore, it has been difficult to definitively conclude whether $D G K H$ is related to $\mathrm{BPD}$.

All of the SNPs in DGKH that are implicated in the etiology of BPD by GWASs are located in introns and $3^{\prime}$-flank region (Table 1). For example, the SNPs rs9315885 and rs1170191, which are identified in multiple independent reports (Baum et al., 2008; Ollila et al., 2009; Weber et al., 2011), are located in the first intron of $D G K H$. Therefore, it is likely that the SNPs lead to dysregulation of the expression and generation of splice variants of DGK $\eta$, which probably cause BPD.

DGK $\eta$ is known to be most abundantly expressed in the brain (Klauck et al., 1996; Usuki et al., 2015). Interestingly, the expression of DGK $\eta$ increased between 1 and 4 weeks after birth, which coincides with synapse formation in the brain (Usuki et al., 2015). Moreover, a substantial amount of DGK $\eta$ was detected in layers II-VI of the cerebral cortex; in the CA1, CA2, and dentate gyrus regions of the hippocampus; in the mitral cell and glomerular layer of the olfactory bulb; and in the Purkinje cells in the cerebellum of one-to 32-week-old mice (Usuki et al., 2015).

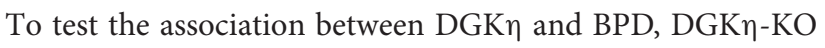
mice are required. However, the generation of DGK $\eta-\mathrm{KO}$ mice has not been accomplished until recently. In our recent study, we succeeded in generating $\mathrm{DGK} \eta-\mathrm{KO}$ mice, and performed a comprehensive behavioral analysis of the mice (Isozaki et al., 2016) to investigate the role of DGK $\eta$ in higher brain functions and the relationship between this isozyme and BPD. $\mathrm{DGK} \eta \mathrm{KO}$ mice exhibited increased open field activity (the frequency of behavioral switching hyperactivity), increased open field center time/frequency (antianxiety), increased open arm 
TABLE 1 | Summary of disease-associated SNPs of DGK $\eta, \kappa, \theta, \gamma, \delta$, and $\iota$.

\begin{tabular}{|c|c|c|c|c|c|}
\hline SNP name & Allele & Location & Gene & Disease/medical condition & References \\
\hline rs9315885 & $\mathrm{T}$ & $13 q 14.11$ & DGKn (Intron 1) & BPD & $\begin{array}{l}\text { Baum et al., 2008; Ollila } \\
\text { et al., } 2009\end{array}$ \\
\hline rs1012053 & A & $13 q 14.11$ & DGKn (Intron 1) & BPD & Baum et al., 2008 \\
\hline \multirow[t]{2}{*}{ rs1170191 } & $\mathrm{C} / \mathrm{A}$ & $13 q 14.11$ & DGKn (Intron 1) & BPD & Baum et al., 2008 \\
\hline & & & & UPD & Weber et al., 2011 \\
\hline \multirow[t]{3}{*}{ rs1170169 } & $\mathrm{G}$ & $13 q 14.11$ & DGKn (Intron 1) & BPD & Weber et al., 2011 \\
\hline & & & & UPD & Weber et al., 2011 \\
\hline & & & & ADHD & Weber et al., 2011 \\
\hline rs2148004 & $\mathrm{G}$ & $13 q 14.11$ & DGKn (Intron 1) & UPD & Weber et al., 2011 \\
\hline \multirow[t]{3}{*}{ rs994856 } & $\mathrm{G}$ & $13 q 14.11$ & DGKn (Intron 3) & BPD & Weber et al., 2011 \\
\hline & & & & UPD & Weber et al., 2011 \\
\hline & & & & ADHD & Weber et al., 2011 \\
\hline \multirow[t]{3}{*}{ rs9525580 } & A & $13 q 14.11$ & DGKn (Intron 3) & BPD & Weber et al., 2011 \\
\hline & & & & UPD & Weber et al., 2011 \\
\hline & & & & ADHD & Weber et al., 2011 \\
\hline \multirow[t]{2}{*}{ rs9525584 } & C & $13 q 14.11$ & DGKn (Intron 7) & BPD & Weber et al., 2011 \\
\hline & & & & UPD & Weber et al., 2011 \\
\hline \multirow[t]{2}{*}{ rs1170101 } & $\mathrm{G}$ & $13 q 14.11$ & DGKn (Intron 20) & BPD & Weber et al., 2011 \\
\hline & & & & UPD & Weber et al., 2011 \\
\hline rs347405 & C & $13 q 14.11$ & DGKn (Intron 26) & ADHD & Weber et al., 2011 \\
\hline rs2122246 & G & $13 q 14.11$ & DGKn (Intron 14) & BPD & Zeng et al., 2011 \\
\hline rs1170099 & A & $13 q 14.11$ & DGKn (Intron 20) & SCZ & Zeng et al., 2011 \\
\hline rs1934179 & $\mathrm{A} / \mathrm{G}$ & Xp11.22 & DGKк (Intron 1) & Hypospadias & $\begin{array}{l}\text { van der Zanden et al., 2011; } \\
\text { Carmichael et al., } 2013\end{array}$ \\
\hline rs7063116 & A & Xp11.22 & DGKк (5' upstream) & Hypospadias & $\begin{array}{l}\text { van der Zanden et al., 2011; } \\
\text { Carmichael et al., } 2013\end{array}$ \\
\hline rs5961179 & G & Xp11.22 & DGKк (Exon 15, synonymous codon) & Hypospadias & Carmichael et al., 2013 \\
\hline rs7882950 & $\mathrm{T}$ & Xp11.22 & DGKK (Intron 14) & Hypospadias & Carmichael et al., 2013 \\
\hline rs12556919 & $\mathrm{T}$ & Xp11.22 & DGKк (Intron 13) & Hypospadias & Carmichael et al., 2013 \\
\hline rs17003341 & $\mathrm{T}$ & Xp11.22 & DGKK (Intron 10) & Hypospadias & Carmichael et al., 2013 \\
\hline rs1934190 & G & Xp11.22 & DGKк (Intron 8) & Hypospadias & Carmichael et al., 2013 \\
\hline rs4143304 & $\mathrm{T}$ & Xp11.22 & DGKк (Exon 6, synonymous codon) & Hypospadias & Carmichael et al., 2013 \\
\hline rs1934188 & $\mathrm{T}$ & Xp11.22 & DGKк (Intron 4) & Hypospadias & Carmichael et al., 2013 \\
\hline rs17328236 & G & Xp11.22 & DGKк (Intron 1) & Hypospadias & Carmichael et al., 2013 \\
\hline rs9969978 & C & Xp11.22 & DGKк (Intron 1) & Hypospadias & Carmichael et al., 2013 \\
\hline rs1934183 & $\mathrm{T}$ & Xp11.22 & DGKк (Intron 1) & Hypospadias & Carmichael et al., 2013 \\
\hline rs6614511 & $\mathrm{T}$ & Xp11.22 & DGKк (Intron 1) & Hypospadias & Carmichael et al., 2013 \\
\hline rs5961183 & C & Xp11.22 & DGKK (Intron 1) & Hypospadias & Carmichael et al., 2013 \\
\hline rs7876567 & $\mathrm{T}$ & Xp11.22 & DGKк (Intron 1) & Hypospadias & Carmichael et al., 2013 \\
\hline rs1564282 & $\mathrm{T} / \mathrm{A}$ & $4 p 16.3$ & DGK $\theta$ (3' downstream) & Parkinson's disease & Pankratz et al., 2009 \\
\hline rs11248060 & $\mathrm{T} / \mathrm{A}$ & $4 p 16.3$ & DGK $\theta$ (Intron 2) & Parkinson's disease & Pankratz et al., 2009 \\
\hline rs7647305 & $\mathrm{C}$ & $3 q 27.2$ & DGK $\gamma$ (3' downstream) & $\mathrm{BMl}$ & Melén et al., 2010 \\
\hline rs6798931 & $\mathrm{G} / \mathrm{C}$ & $3 q 27.2$ & DGK $\gamma$ (Intron 19) & $\mathrm{BMl}$ & Melén et al., 2010 \\
\hline rs11706414 & $\mathrm{T} / \mathrm{A}$ & $3 q 27.2$ & $\mathrm{DGK} \gamma\left(3^{\prime}\right.$ downstream) & Asthma & Melén et al., 2010 \\
\hline rs888383 & $\mathrm{C} / \mathrm{G}$ & $3 q 27.2$ & DGK $\gamma$ (Intron 19) & Asthma & Melén et al., 2010 \\
\hline rs1550532 & C & 2q37.1 & DGK $\delta$ (Intron 1) & Bone density & O'Seaghdha et al., 2013 \\
\hline rs161339 & G & 7q32.3 & DGKı (3' downstream) & Obesity/BMI & Laramie et al., 2009 \\
\hline
\end{tabular}

BPD, bipolar disorder; UPD, unipolar depression; ADHD, attention deficit hyperactivity disorder; SCZ, schizophrenia; BMI, body mass index.

time/frequency in elevated plus maze (antianxiety), and increased antidepressant-like behavior (Isozaki et al., 2016). Moreover, these phenotypes were sensitive to a BPD remedy, lithium. The behavioral profile (hyperactivity, lower anxiety, lower depressive states, and cognitive impairment) of DGK $\eta$-KO mice is similar in behavioral dimensions to $\mathrm{BPD}$ patients in the manic state 
(Martinowich et al., 2009), including the disappearance of the phenotypes upon lithium treatment. These lithium-sensitive phenotypes have been commonly observed in representative BPD model mice, such as neurocan-KO (Miró et al., 2012), clock-KO (Roybal et al., 2007), glutamate receptor 6-KO (Shaltiel et al., 2008), DGK $\beta$-KO (Kakefuda et al., 2010; Shirai et al., 2010), and glycogen synthase kinase 3 $\beta$-transgenic (Spittaels et al., 2000; Prickaerts et al., 2006) mice. Therefore, these findings strongly suggest that DGK $\eta$ is one of the key enzymes related to BPD pathogenesis and support the GWAS results. The lack of availability of suitable animal models of mania has been one of the greatest impediments in the field. Our results indicate that the DGK $\eta-\mathrm{KO}$ mice would represent a bona fide model of human BPD with mania. Therefore, it is likely that these mice are particularly useful for studying the pathophysiology of mania. Moreover, DGK $\eta$-specific inhibitors can be good remedies for BPD patients in the depressive state.

DGK $\eta$ has also been found to be associated with attention deficit hyperactivity disorder (ADHD) by GWAS (Weber et al., 2011). Moreover, mania-like behaviors are similar to ADHD symptoms. Therefore, DGK $\eta-\mathrm{KO}$ mice could also represent a model for ADHD, and there may be a possible link between DGK $\eta$ and ADHD in addition to BPD (Table 1). GWASs have also implied that DGK $\eta$ is associated with unipolar depression (Weber et al., 2011), and schizophrenia (Zeng et al., 2011). It is also interesting to investigate the relationship between DGK $\eta$ and unipolar depression/schizophrenia. DGK $\eta$ may commonly play pivotal roles in the pathology of these four psychoses.

DGK $\eta$-KO mice showed impairment in glycogen synthase kinase $3 \beta$ signaling (Isozaki et al., 2016), which is closely related to BPD (Spittaels et al., 2000; Prickaerts et al., 2006). However, it is still unclear how DGK $\eta$ is involved in the etiology of BPD. Phosphatidylinositol turnover has been hypothesized to play an important role in the mechanism of action of lithium (Martinowich et al., 2009). DGK is one of the components of phosphatidylinositol turnover (Goto et al., 2006; Sakane et al., 2007; Mérida et al., 2008; Topham and Epand, 2009). Moreover, we recently found that the pleckstrin homology domain of DGK $\eta$ is selectively and strongly bound to phosphatidylinositol 4,5-bisphosphate, a product of phosphatidylinositol turnover (Kume et al., 2016). We also revealed that DGK $\eta$ is a unique enzyme with high affinity for DG (Komenoi et al., 2015). In addition, DGK $\eta$ is a positive regulator of the epidermal growth factor receptor/Raf/MEK/ERK pathway (Yasuda et al., 2009), which drives phosphatidylinositol turnover and is related to BPD (Sklar et al., 2008). It will be interesting to determine what role DGK $\eta$ plays in the phosphatidylinositol turnover-related, lithium-sensitive molecular mechanisms of BPD pathogenesis.

\section{DGKк}

Hypospadias is a common congenital hypoplasia of the penis, affecting $\sim 1$ in 750 births in Europe. It is believed that hypospadias is caused by sex hormonal disturbances. In fact, genetic polymorphisms in endocrine-related genes such as estrogen receptors have been associated with hypospadias
(Ban et al., 2008). To further identify the genetic variants in hypospadias, van der Zanden et al. performed the first GWAS using European samples of anterior or middle hypospadias patients and found that two SNPs, rs1934179 and rs7063116, in $D G K \kappa$, which mapped to Xp11.22 and encodes DGKк, exhibited a significant association (van der Zanden et al., 2011; Table 1). The authors also found SNPs in DGKK in additional Dutch and Swedish cohorts of anterior or middle hypospadias cases. Carmichael et al. confirmed that $D G K \kappa$ variants are associated with hypospadias in a more racially/ethnically diverse study population of California births (Carmichael et al., 2013). In addition to rs1934179 and rs7063116, several other SNPs in $D G K \kappa$ are associated with the disease. DGK $\mathrm{mRNA}$ is most abundant in the testis and placenta (Imai et al., 2005), and the study of van der Zanden et al. showed that expression of $D G K \kappa$ was lower in preputial tissues in carriers of the risk allele rs1934179 (van der Zanden et al., 2011). These results indicate that $D G K \kappa$ is a major risk gene for hypospadias.

\section{DGK $\theta$}

Parkinson's disease (PD) is a second most common chronic neurodegenerative disease with a cumulative prevalence of greater than one per thousand people (Kuopio et al., 1999). Mutations in five genes have been identified to influence PD risk in fewer than 5\% of those with PD (Pankratz and Foroud, 2007). Three genes, PARK2 (parkin), PARK7 (DJ1), and PINK1, are typically transmitted with autosomal recessive inheritance and two, SNCA and LRRK2, are inherited in an autosomal dominant fashion. Mutations in all but LRRK2 are typically found in early onset PD.

In addition to those five genes, two SNPs, rs1564282 and rs11248060, in the GAK (cyclin G associated kinase, a cell cycle regulator)/DGKQ (DGK $\theta$ ) region were repeatedly reported to be associated with PD by Pankratz et al. (2009), and Simón-Sánchez et al. (2011) (Table 1). DGK $\theta$ is abundantly expressed in the brain (Houssa et al., 1997). Thus, these data suggest the identification of new susceptibility alleles for PD in the GAK/DGKQ region.

\section{Other DGK Isozymes}

genome-wide association studies have suggested that several other DGK isozymes are associated with diseases and medical conditions as follows: DGK $\gamma$ : asthma (rs11706414, s888383) and obesity (rs7647305, rs6798931) in children (Melén et al., 2010); DGK $\delta$ (rs1550532): bone mineral density (O'Seaghdha et al., 2013); and DGKı (rs161339): obesity/body mass index (Laramie et al., 2009; Table 1).

\section{SPECIFIC INHIBITORS FOR DGK ISOZYMES}

DGKa (Sakane et al., 1990; Schaap et al., 1990) is highly expressed in hepatocellular carcinoma and melanoma cells (Yanagisawa et al., 2007; Takeishi et al., 2012). DGK $\alpha$ expression is involved in hepatocellular carcinoma progression and is a positive regulator of the proliferative activity of hepatocellular carcinoma through the Ras/Raf/MEK/ERK pathway (Takeishi et al., 2012). In melanoma cells, $D G K \alpha$ positively regulates 
tumor necrosis factor- $\alpha$-dependent nuclear factor- $\kappa \mathrm{B}$ (p65) activation via the PKC $\zeta$-mediated Ser311 phosphorylation of p65 (Kai et al., 2009). The growth of colon and breast cancer cell lines was significantly inhibited by DGK $\alpha$-siRNA and R59949 (Torres-Ayuso et al., 2014). The DGK $\alpha /$ atypical PKC/ $\beta 1$ integrin signaling pathway is essential for matrix invasion of breast carcinoma cells (Rainero et al., 2014). Therefore, the suppression of DGK $\alpha$ activity is expected to inhibit the progression of these cancers. On the other hand, DGK $\alpha$ is abundantly expressed in T lymphocytes, where it facilitates the non-responsive state known as anergy (Olenchock et al., 2006; Zha et al., 2006). Anergy induction in T cells represents the main mechanism by which advanced tumors avoid immune action. Therefore, if a DGK $\alpha$-selective inhibitor is identified and developed, it would reversely attenuate cancer cell proliferation and simultaneously activate $\mathrm{T}$ cell function and can be a dual effective compound.

We started the "Dual effective DGK $\alpha$-selective inhibitor project" in 2009. To develop highly effective and DGK $\alpha$ selective inhibitors, a system for high-throughput screening is required; however, the conventional DGK assay is quite laborious and requires technical skill. For example, the conventional assay requires the use of a radioisotope $\left(\left[\gamma^{-32} \mathrm{P}\right] \mathrm{ATP}\right)$ and the manipulation of thin-layer chromatography with multiple extraction steps. We recently established a simple DGK assay (Sato et al., 2013) that is useful for constructing a highthroughput screening system for detecting DGK inhibitors from chemical compound libraries.

We screened a library containing core 9600 compounds (Drug Discovery Initiative, The University of Tokyo) using a high-throughput chemiluminescence-based assay. We obtained several compounds that inhibited the $\alpha$-isozyme of DGK. Among the compounds, CU-3, 5-[(2E)-3-(2-furyl)prop-2-enylidene]3-[(phenylsulfonyl)amino]-2-thioxo-1,3-thiazolidin-4-one was identified as a potent and selective inhibitor against the DGK $\alpha$ (Liu et al., 2016). Compared with commercially available DGK inhibitors, such as R59022 and R59949 (Sato et al., 2013), CU-3 exhibited higher efficiency and selectivity against DGK $\alpha$. The $\mathrm{IC}_{50}$ value of CU-3 $(0.6 \mu \mathrm{M})$ was markedly lower than the values of R59022 and R59949 ( 25 and $18 \mu \mathrm{M}$, respectively; Sato et al., 2013). R59022 and R59949 only semi-selectively inhibited type I, III and V DGKs $\alpha, \varepsilon$, and $\theta$, and type I and II DGKs $\alpha$, $\gamma, \delta$, and $\kappa$, respectively (Sato et al., 2013). However, the $\mathrm{IC}_{50}$ value of CU-3 for DGK $\alpha$ was at least $\sim 12$ times lower than the values for other DGK isozymes. Therefore, this study is the first report of a highly $\alpha$-isozyme selective inhibitor. The target of CU-3 is the catalytic domain of DGK $\alpha$, and CU-3 competitively reduced the affinity of DGK $\alpha$ for ATP but not diacylglycerol or phosphatidylserine, strongly suggesting that CU-3 competes with ATP binding.

CU-3 induced apoptosis in HepG2 hepatocellular carcinoma and HeLa cervical cancer cells (Liu et al., 2016). Supporting our results, Torres-Ayuso et al. (Torres-Ayuso et al., 2014) also demonstrated that the growth of colon and breast cancer cell lines was significantly inhibited by DGK $\alpha$-siRNA and R59949. In addition, Dominguez et al. reported that DGK $\alpha$ siRNA and R59022 negatively affected the proliferation of glioblastoma, melanoma, breast cancer, and cervical cancer cells (Dominguez et al., 2013). The authors also observed that in marked contrast to cancer cells, R59022 did not weaken the growth of non-cancerous astrocytes and fibroblasts (Dominguez et al., 2013). CU-3 also failed to increase the caspase 3/7 activity of the non-cancer-derived COS-7 cells. These findings suggest that CU-3 selectively induces apoptosis.

In addition to the induction of cancer cell apoptosis, we found that CU-3 promoted IL-2 production, which is one of the indicators of T cell activation. Because inactivation (anergy induction) of $\mathrm{T}$ cells is the main mechanism by which advanced tumors to avoid immune action, it is expected that CU-3 is able to activate cancer immunity.

General anti-cancer drugs inhibit the proliferation and function of both cancer and bone marrow cells (Chabner and Roberts, 2005; Pérez-Herrero and FernándezMedarde, 2015). Therefore, they induce not only the attenuation of cancer cell proliferation but also bone marrow suppression/myelosuppression, which is one of the most commonly observed side-effects of anti-cancer drugs. However, there is no drug that has both pro-tumoral and anti-immunogenic effects. The DGK $\alpha$-selective inhibitor would simultaneously have anti-tumoral and pro-immunogenic effects (Figure 1). Therefore, in addition to the direct effects on apoptosis induction in cancer cells, CU-3 can indirectly induce the death of cancer cells through activation of the immune system. Moreover, CU-3 can be an effective tool for biological science concerning cancer and immunity.

CU-3 still does not have sufficient isozyme selectivity and efficiency as an excellent inhibitor. Moreover, comprehensive studies where other kinase groups are tested have not been performed. Further refinement of $\mathrm{CU}-3$ and/or identification/development of new candidates using larger chemical compound libraries are required. Finally, our current results encourage us to identify and develop specific

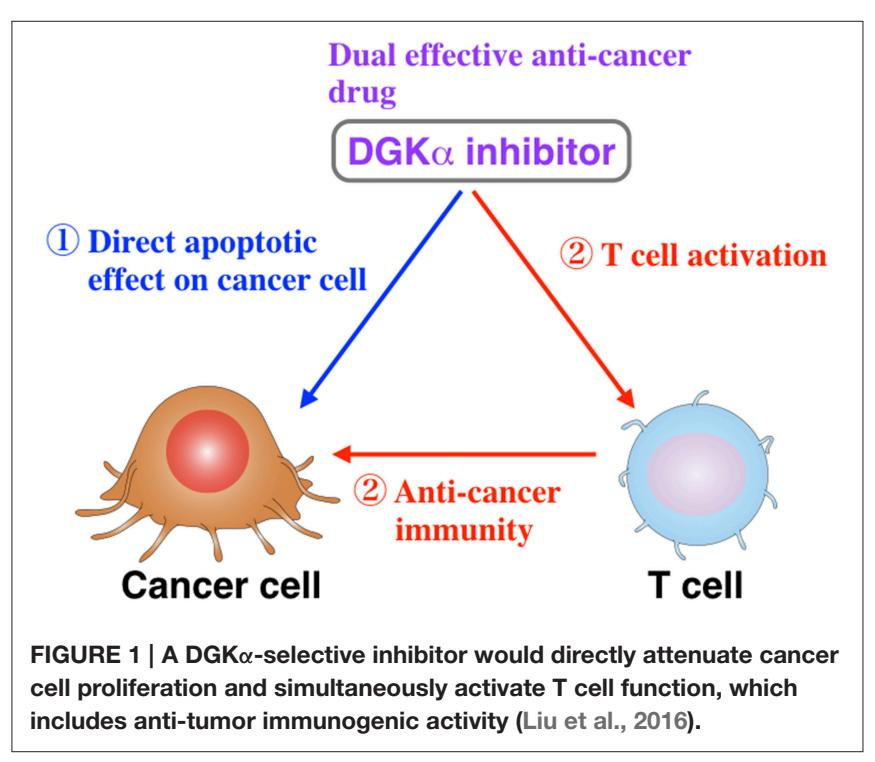


inhibitors/activators against every DGK isozyme that can be effective regulators and drugs against a wide variety of physiological events and diseases, although the ten DGK isozymes are highly similar to each other.

\section{REFERENCES}

Ban, S., Sata, F., Kurahashi, N., Kasai, S., Moriya, K., Kakizaki, H., et al. (2008). Genetic polymorphisms of ESR1 and ESR2 that may influence estrogen activity and the risk of hypospadias. Hum. Reprod. 23, 1466-1471. doi: 10.1093/humrep/den098

Bauer, M., and Pfennig, A. (2005). Epidemiology of bipolar disorders. Epilepsia 46(Suppl. 4), 8-13. doi: 10.1111/j.1528-1167.2005.463003.x

Baum, A. E., Akula, N., Cabanero, M., Cardona, I., Corona, W., Klemens, B., et al. (2008). A genome-wide association study implicates diacylglycerol kinase eta (DGKH) and several other genes in the etiology of bipolar disorder. Mol. Psychiatry 13, 197-207. doi: 10.1038/sj.mp.4002012

Bunting, M., Tang, W., Zimmerman, G. A., McIntyre, T. M., and Prescott, S. M. (1996). Molecular cloning and characterization of a novel human diacylglycerol kinase zeta. J. Biol. Chem. 271, 10230-10236. doi: 10.1074/jbc.271.1 7.10237

Carmichael, S. L., Mohammed, N., Ma, C., Iovannisci, D., Choudhry, S., Baskin, L. S., et al. (2013). Diacylglycerol kinase K variants impact hypospadias in a California study population. J. Urol. 189, 305-311. doi: 10.1016/j.juro.2012.09.002

Chabner, B. A., and Roberts, T. G. Jr. (2005). Timeline: chemotherapy and the war on cancer. Nat. Rev. Cancer 5, 65-72. doi: 10.1038/nrc1529

Ding, L., Traer, E., McIntyre, T. M., Zimmerman, G. A., and Prescott, S. M. (1998). The cloning and characterization of a novel human diacylglycerol kinase, DGKiota. J. Biol. Chem. 273, 32746-32752. doi: 10.1074/jbc.273.4 9.32746

Ding, L., Bunting, M., Topham, M. K., McIntyre, T. M., Zimmerman, G. A., and Prescott, S. M. (1997). Alternative splicing of the human diacylglycerol kinase $\zeta$ gene in muscle. Proc. Natl. Acad. Sci. U.S.A. 94, 5519-5524. doi: 10.1073/pnas.94.11.5519

Dominguez, C. L., Floyd, D. H., Xiao, A., Mullins, G. R., Kefas, B. A., Xin, W., et al. (2013). Diacylglycerol kinase $\alpha$ is a critical signaling node and novel therapeutic target in glioblastoma and other cancers. Cancer Discov. 3, 782-797. doi: 10.1158/2159-8290.CD-12-0215

Goto, K., and Kondo, H. (1993). Molecular cloning and expression of a 90-kDa diacylglycerol kinase that predominantly localizes in neurons. Proc. Natl. Acad. Sci. U.S.A. 90, 7598-7602. doi: 10.1073/pnas.90.16.7598

Goto, K., and Kondo, H. (1996). A 104-kDa diacylglycerol kinase containing ankylin-like repeats localizes in the cell nucleus. Proc. Natl. Acad. Sci. U.S.A. 93, 11196-11201. doi: 10.1073/pnas.93.20.11196

Goto, K., Funayama, M., and Kondo, H. (1994). Cloning and expression of a cytoskeleton-associated diacylglycerol kinase that is dominantly expressed in cerebellum. Proc. Natl. Acad. Sci. U.S.A. 91, 13042-13046. doi: $10.1073 /$ pnas. 91.26 .13042

Goto, K., Hozumi, Y., and Kondo, H. (2006). Diacylglycerol, phosphatidic acid, and the converting enzyme, diacylglycerol kinase, in the nucleus. Biochim. Biophys. Acta 1761, 535-541. doi: 10.1016/j.bbalip.2006. 04.001

Houssa, B., Schaap, D., van der Val, J., Goto, K., Kondo, H., Yamakawa, A., et al. (1997). Cloning of a Novel Human Diacylglycerol Kinase (DGK $\theta$ ) containing three cysteine-rich domains, a proline-rich region, and a pleckstrin homology domain with an overlapping ras-associating domain. J. Biol. Chem. 272, 10422-10428. doi: 10.1074/jbc.272.16.10422

Imai, S., Kai, M., Yasuda, S., Kanoh, H., and Sakane, F. (2005). Identification and characterization of a novel human type II diacylglycerol kinase, DGKK. J. Biol. Chem. 280, 39870-39881. doi: 10.1074/jbc.M500669200

Isozaki, T., Komenoi, S., Lu, Q., Usuki, T., Tomokata, S., Matsutomo, D., et al. (2016). Deficiency of diacylglycerol kinase eta induces lithiumsensitive mania-like behavior. J. Neurochem. 138, 448-456. doi: 10.1111/jn c. 13661

\section{AUTHOR CONTRIBUTIONS}

All authors listed, have made substantial, direct and intellectual contribution to the work, and approved it for publication.

Ito, T., Hozumi, Y., Sakane, F., Saino-Saito, S., Kanoh, H., Aoyagi, M., et al. (2004). Cloning and characterization of diacylglycerol kinase ı splice variants in rat brain. J. Biol. Chem. 279, 23317-23326. doi: 10.1074/jbc.M3129 76200

Kai, M., Sakane, F., Imai, S., Wada, I., and Kanoh, H. (1994). Molecular cloning of a diacylglycerol kinase isozyme predominantly expressed in human retina with a truncated and inactive enzyme expression in most other human cells. J. Biol. Chem. 269, 18492-18498.

Kai, M., Yasuda, S., Imai, S., Toyota, M., Kanoh, H., and Sakane, F. (2009). Diacylglycerol kinase $\alpha$ enhances protein kinase $C \zeta$-dependent phosphorylation at Ser311 of p65/RelA subunit of nuclear factor-кB. FEBS Lett. 583, 3265-3268. doi: 10.1016/j.febslet.2009.09.017

Kakefuda, K., Oyagi, A., Ishisaka, M., Tsuruma, K., Shimazawa, M., Yokota, K., et al. (2010). Diacylglycerol kinase $\beta$ knockout mice exhibit lithium-sensitive behavioral abnormalities. PLoS ONE 5:e13447. doi: 10.1371/journal.pone.0013447

Kilbane, E. J., Gokbayrak, N. S., Galynker, I., Cohen, L., and Tross, S. (2009). A review of panic and suicide in bipolar disorder: does comorbidity increase risk? J. Affect. Disord. 115, 1-10. doi: 10.1016/j.jad.2008.09.014

Klauck, T. M., Xu, X., Mousseau, B., and Jaken, S. (1996). Cloning and characterization of a glucocorticoid-induced diacylglycerol kinase. J. Biol. Chem. 271, 19781-19788. doi: 10.1074/jbc.271.33.19781

Komenoi, S., Takemura, F., Sakai, H., and Sakane, F. (2015). Diacylglycerol kinase $\eta 1$ is a high affinity isozyme for diacylglycerol. FEBS Lett. 589, 1272-1277. doi: 10.1016/j.febslet.2015.03.032

Kume, A., Kawase, K., Komenoi, S., Usuki, T., Takeshita, E., Sakai, H., et al. (2016). The pleckstrin homology domain of diacylglycerol kinase eta strongly and selectively binds to phosphatidylinositol 4,5-bisphosphate. J. Biol. Chem. 291, 8150-8161. doi: 10.1074/jbc.M115.648717

Kuopio, A. M., Marttila, R. J., Helenius, H., and Rinne, U. K. (1999). Changing epidemiology of Parkinson's disease in southwestern Finland. Neurology 52, 302-308. doi: 10.1212/WNL.52.2.302

Laramie, J. M., Wilk, J. B., Williamson, S. L., Nagle, M. W., Latourelle, J. C., Tobin, J. E., et al. (2009). Multiple genes influence BMI on chromosome 7q3134: the NHLBI Family Heart Study. Obesity 17, 2182-2189. doi: 10.1038/oby. 2009.141

Liu, K., Kunii, N., Sakuma, M., Yamaki, A., Mizuno, S., Sato, M., et al. (2016). A novel diacylglycerol kinase $\alpha$-selective inhibitor, CU-3, induces cancer cell apoptosis and enhances immune response. J. Lipid Res. 57, 368-379. doi: 10.1194/jlr.M062794

Martinowich, K., Schloesser, R. J., and Manji, H. K. (2009). Bipolar disorder: from genes to behavior pathways. J. Clin. Invest. 119, 726-736. doi: 10.1172/JCI 37703

Melén, E., Himes, B. E., Brehm, J. M., Boutaoui, N., Klanderman, B. J., Sylvia, J. S., et al. (2010). Analyses of shared genetic factors between asthma and obesity in children. J. Allergy Clin. Immunol. 126, 631-637.e631-e638. doi: 10.1016/j.jaci.2010.06.030

Mérida, I., Avila-Flores, A., and Merino, E. (2008). Diacylglycerol kinases: at the hub of cell signalling. Biochem. J. 409, 1-18. doi: 10.1042/BJ200 71040

Merikangas, K. R., Akiskal, H. S., Angst, J., Greenberg, P. E., Hirschfeld, R. M., Petukhova, M., et al. (2007). Lifetime and 12-month prevalence of bipolar spectrum disorder in the National Comorbidity Survey replication. Arch. Gen. Psychiatry 64, 543-552. doi: 10.1001/archpsyc.64.5.543

Miró, X., Meier, S., Dreisow, M. L., Frank, J., Strohmaier, J., Breuer, R., et al. (2012). Studies in humans and mice implicate neurocan in the etiology of mania. Am. J. Psychiatry 169, 982-990. doi: 10.1176/appi.ajp.2012.111 01585

Moya, P. R., Murphy, D. L., McMahon, F. J., and Wendland, J. R. (2010). Increased gene expression of diacylglycerol kinase eta in bipolar disorder. 
Int. J. Neuropsychopharmacol. 13, 1127-1128. doi: 10.1017/S1461145710 000593

Murakami, T., Sakane, F., Imai, S., Houkin, K., and Kanoh, H. (2003). Identification and characterization of two splice variants of human diacylglycerol kinase $\eta$. J. Biol. Chem. 278, 34364-34372. doi: 10.1074/jbc.M301542200

O’Seaghdha, C. M., Wu, H., Yang, Q., Kapur, K., Guessous, I., Zuber, A. M., et al. (2013). Meta-analysis of genome-wide association studies identifies six new Loci for serum calcium concentrations. PLoS Genet. 9:e1003796. doi: 10.1371/journal.pgen.1003796

Olenchock, B. A., Guo, R., Carpenter, J. H., Jordan, M., Topham, M. K., Koretzky, G. A., et al. (2006). Disruption of diacylglycerol metabolism impairs the induction of T cell anergy. Nat. Immunol. 7, 1174-1181. doi: 10.1038/ ni1400

Ollila, H. M., Soronen, P., Silander, K., Palo, O. M., Kieseppä, T., Kaunisto, M. A., et al. (2009). Findings from bipolar disorder genome-wide association studies replicate in a Finnish bipolar family-cohort. Mol. Psychiatry 14, 351-353. doi: 10.1038/mp.2008.122

Pankratz, N., and Foroud, T. (2007). Genetics of Parkinson disease. Genet. Med. 9, 801-811. doi: 10.1097/GIM.0b013e31815bf97c

Pankratz, N., Wilk, J. B., Latourelle, J. C., DeStefano, A. L., Halter, C., Pugh, E. W., et al. (2009). Genomewide association study for susceptibility genes contributing to familial Parkinson disease. Hum. Genet. 124, 593-605. doi: 10.1007/s00439-008-0582-9

Pérez-Herrero, E., and Fernández-Medarde, A. (2015). Advanced targeted therapies in cancer: drug nanocarriers, the future of chemotherapy. Eur. J. Pharm. Biopharm. 93, 52-79. doi: 10.1016/j.ejpb.2015.03.018

Prickaerts, J., Moechars, D., Cryns, K., Lenaerts, I., van Craenendonck, H., Goris, I., et al. (2006). Transgenic mice overexpressing glycogen synthase kinase 3beta: a putative model of hyperactivity and mania. J. Neurosci. 26, 9022-9029. doi: 10.1523/JNEUROSCI.5216-05.2006

Rainero, E., Cianflone, C., Porporato, P. E., Chianale, F., Malacarne, V., Bettio, V., et al. (2014). The diacylglycerol kinase alpha/atypical PKC/betal integrin pathway in SDF-1alpha mammary carcinoma invasiveness. PLoS ONE 9:e97144. doi: 10.1371/journal.pone.0097144

Roybal, K., Theobold, D., Graham, A., DiNieri, J. A., Russo, S. J., Krishnan, V., et al. (2007). Mania-like behavior induced by disruption of CLOCK. Proc. Natl. Acad. Sci. U.S.A. 104, 6406-6411. doi: 10.1073/pnas.0609625104

Sakane, F., Yamada, K., Kanoh, H., Yokoyama, C., and Tanabe, T. (1990). Porcine diacylglycerol kinase sequence has zinc finger and E-F hand motifs. Nature 344, 345-348. doi: 10.1038/344345a0

Sakane, F., Imai, S., Kai, M., Wada, I., and Kanoh, H. (1996). Molecular cloning of a novel diacylglycerol kinase isozyme with a pleckstrin homology domain and a C-terminal tail similar to those of the EPH family of protein tyrosine kinase. J. Biol. Chem. 271, 8394-8401. doi: 10.1074/jbc.271.14.8394

Sakane, F., Imai, S., Kai, M., Yasuda, S., and Kanoh, H. (2007). Diacylglycerol kinases: why so many of them? Biochim. Biophys. Acta 1771, 793-806. doi: 10.1016/j.bbalip.2007.04.006

Sakane, F., Imai, S., Kai, M., Yasuda, S., and Kanoh, H. (2008). Diacylglycerol kinases as emerging potential drug targets for a variety of diseases. Curr. Drug Targets 9, 626-640. doi: 10.2174/138945008785132394

Sakane, F., Imai, S., Yamada, K., Murakami, T., Tsushima, S., and Kanoh, H. (2002). Alternative splicing of the human diacylglycerol kinase $\delta$ gene generates two isoforms differing in their expression patterns and in regulatory functions. J. Biol. Chem. 277, 43519-43526. doi: 10.1074/jbc.M206895200

Sato, M., Liu, K., Sasaki, S., Kunii, N., Sakai, H., Mizuno, H., et al. (2013). Evaluations of the selectivities of the diacylglycerol kinase inhibitors R59022 and R59949 among diacylglycerol kinase isozymes using a new non-radioactive assay method. Pharmacology 92, 99-107. doi: 10.1159/000351849

Schaap, D., de Widt, J., van der Wal, J., Vandekerckhove, J., van Damme, J., Gussow, D., et al. (1990). Purification, cDNA-cloning and expression of human diacylglycerol kinase. FEBS Lett. 275, 151-158. doi: 10.1016/00145793(90)81461-V

Shaltiel, G., Maeng, S., Malkesman, O., Pearson, B., Schloesser, R. J., Tragon, T., et al. (2008). Evidence for the involvement of the kainate receptor subunit GluR6 (GRIK2) in mediating behavioral displays related to behavioral symptoms of mania. Mol. Psychiatry 13, 858-872. doi: 10.1038/mp. 2008.20
Shionoya, T., Usuki, T., Komenoi, S., Isozaki, T., Sakai, H., and Sakane, F. (2015). Distinct expression and localization of the Type II diacylglycerol kinase isozymes $\delta, \eta$ and $\kappa$ in the mouse reproductive organs. BMC Dev. Biol. 15:6. doi: 10.1186/s12861-015-0055-Z

Shirai, Y., Kouzuki, T., Kakefuda, K., Moriguchi, S., Oyagi, A., Horie, K., et al. (2010). Essential role of neuron-enriched diacylglycerol kinase (DGK), DGK $\beta$ in neurite spine formation, contributing to cognitive function. PLOS ONE 5:e11602. doi: 10.1371/journal.pone.0011602

Simón-Sánchez, J., van Hilten, J. J., van de Warrenburg, B., Post, B., Berendse, H. W., Arepalli, S., et al. (2011). Genome-wide association study confirms extant PD risk loci among the Dutch. Eur. J. Hum. Genet. 19, 655-661. doi: 10.1038/ejhg.2010.254

Sklar, P., Smoller, J. W., Fan, J., Ferreira, M. A., Perlis, R. H., Chambert, K., et al. (2008). Whole-genome association study of bipolar disorder. Mol. Psychiatry 13, 558-569. doi: 10.1038/sj.mp.4002151

Spittaels, K., Van den Haute, C., Van Dorpe, J., Geerts, H., Mercken, M., Bruynseels, K., et al. (2000). Glycogen synthase kinase-3beta phosphorylates protein tau and rescues the axonopathy in the central nervous system of human four-repeat tau transgenic mice. J. Biol. Chem. 275, 41340-41349. doi: 10.1074/jbc.M006219200

Squassina, A., Manchia, M., Congiu, D., Severino, G., Chillotti, C., Ardau, R., et al. (2009). The diacylglycerol kinase eta gene and bipolar disorder: a replication study in a Sardinian sample. Mol. Psychiatry 14, 350-351. doi: 10.1038/mp.2008.93

Takeishi, K., Taketomi, A., Shirabe, K., Toshima, T., Motomura, T., Ikegami, T., et al. (2012). Diacylglycerol kinase alpha enhances hepatocellular carcinoma progression by activation of Ras-Raf-MEK-ERK pathway. J. Hepatol. 57, 77-83. doi: $10.1016 /$ j.jhep.2012.02.026

Tang, W., Bunting, M., Zimmerman, G. A., McIntyre, T. M., and Prescott, S. M. (1996). Molecular cloning of a novel human diacylglycerol kinase highly selective for arachidonate-containing substrates. J. Biol. Chem. 271, 10237-10241. doi: 10.1074/jbc.271.17.10230

Tesli, M., Kähler, A. K., Andreassen, B. K., Werge, T., Mors, O., Mellerup, E., et al. (2009). No association between DGKH and bipolar disorder in a Scandinavian case-control sample. Psychiatr. Genet. 19, 269-272. doi: 10.1097/YPG.0b013e32832d302f

Topham, M. K., and Epand, R. M. (2009). Mammalian diacylglycerol kinases: molecular interactions and biological functions of selected isoforms. Biochim. Biophys. Acta 1790, 416-424. doi: 10.1016/j.bbagen.2009. 01.010

Torres-Ayuso, P., Daza-Martín, M., Martín-Pérez, J., Ávila-Flores, A., and Mérida, I. (2014). Diacylglycerol kinase $\alpha$ promotes 3D cancer cell growth and limits drug sensitivity through functional interaction with Src. Oncotarget 5 , 9710-9726. doi: 10.18632/oncotarget.2344

Usuki, T., Sakai, H., Shionoya, T., Sato, N., and Sakane, F. (2015). Expression and localization of type II diacylglycerol kinase isozymes delta and eta in the developing mouse brain. J. Histochem. Cytochem. 63, 57-68. doi: $10.1369 / 0022155414559130$

van der Zanden, L. F., van Rooij, I. A., Feitz, W. F., Knight, J., Donders, A. R., Renkema, K. Y., et al. (2011). Common variants in DGKא are strongly associated with risk of hypospadias. Nat. Genet. 43, 48-50. doi: 10.103 8/ng.721

Weber, H., Kittel-Schneider, S., Gessner, A., Domschke, K., Neuner, M., Jacob, C. P., et al. (2011). Cross-disorder analysis of bipolar risk genes: further evidence of DGKH as a risk gene for bipolar disorder, but also unipolar depression and adult ADHD. Neuropsychopharmacology 36, 2076-2085. doi: 10.1038/npp.2011.98

Yanagisawa, K., Yasuda, S., Kai, M., Imai, S., Yamada, K., Yamashita, T., et al. (2007). Diacylglycerol kinase $\alpha$ suppresses tumor necrosis factor- $\alpha$-induced apoptosis of human melanoma cells through NF- $\kappa \mathrm{B}$ activation. Biochim. Biophys. Acta 1771, 462-474. doi: 10.1016/j.bbalip.2006.12.008

Yasuda, S., Kai, M., Imai, S., Takeishi, K., Taketomi, A., Toyota, M., et al. (2009). Diacylglycerol kinase $\eta$ augments C-Raf activity and BRaf/C-Raf heterodimerization. J. Biol. Chem. 284, 29559-29570. doi: 10.1074/jbc.M109.043604

Yosifova, A., Mushiroda, T., Stoianov, D., Vazharova, R., Dimova, I., Karachanak, S., et al. (2009). Case-control association study of 65 candidate genes revealed a possible association of a SNP of HTR5A to be a factor susceptible to 
bipolar disease in Bulgarian population. J. Affect. Disord. 117, 87-97. doi: 10.1016/j.jad.2008.12.021

Zeng, Z., Wang, T., Li, T., Li, Y., Chen, P., Zhao, Q., et al. (2011). Common SNPs and haplotypes in DGKH are associated with bipolar disorder and schizophrenia in the Chinese Han population. Mol. Psychiatry 16, 473-475. doi: 10.1038/mp.2010.86

Zha, Y., Marks, R., Ho, A. W., Peterson, A. C., Janardhan, S., Brown, I., et al. (2006). T cell anergy is reversed by active Ras and is regulated by diacylglycerol kinase- $\alpha$. Nat. Immunol. 7, 1166-1173. doi: 10.1038/n i1394
Conflict of Interest Statement: The authors declare that the research was conducted in the absence of any commercial or financial relationships that could be construed as a potential conflict of interest.

Copyright (๑) 2016 Sakane, Mizuno and Komenoi. This is an open-access article distributed under the terms of the Creative Commons Attribution License (CC BY). The use, distribution or reproduction in other forums is permitted, provided the original author(s) or licensor are credited and that the original publication in this journal is cited, in accordance with accepted academic practice. No use, distribution or reproduction is permitted which does not comply with these terms. 